\title{
Anthropocentrism and the roots of resistance to both human
}

\section{bioenhancement and space colonization}

Milan M. Ćirković

Astronomical Observatory of Belgrade, Volgina 7,

11000 Belgrade, Serbia

e-mail: mcirkoviceaob.rs

\section{Introduction: cartels and regressives}

A cartel is usually defined a group of independent actors with heterogeneous goals, whose one common goal is to improve their profits and/or market position by reducing their mutual competition. A special - or not that special at all - kind of cartel are drug or other criminal cartels in which, for instance, crime families gather in order to monopolize black market of prohibited substances, or in order to efficiently control a territory whose government is weak or corrupt. Historical examples of such cartels are the Italian-Jewish-American Mafia (especially after the famous meeting in Atlantic City in 1929, which was attended by Al Capone, Benjamin "Bugsy" Siegel, Dutch Schultz, representatives of the Gambino clan, and others; cf. Bernstein 2002); Mexican drug cartels like the Gulf Cartel or the Guadalajara Cartel; or the now dissolved Columbian Cali Cartel. The fight against these extreme forms of organized crime is so difficult exactly because of the strong support of their "clients" as long as the cartels enjoy monopolistic position in either a geographical region or a social stratum. Some totalitarian and authoritarian regimes, such as the fascist Italy or Spain under Franco endeavored to construct a total cartel system comprising all or most trades of the economy.

Cartelization exists, however, in the domain of ideas as well - and often has at last as ominous meanings and implications. From sophists in the time of Socrates, to the present-day socialconstructivists on the academic extreme left, thinkers of otherwise heterogeneous bents and interests have joined forces in order to promote particular idea, meme, or the way of thinking, not on the merit of intrinsic value, but on the quasi-Hegelian notion of converting "quantity into quality" and the vernacular "strength in numbers". In the rest of this paper, I wish to briefly defend the following theses:

There is a strong anthropocentric cartel with vested interest in human exceptionalism, geocentrism, and other forms of parochial, self-indulgent, small-scale, and solipsist thinking. 
$>$ The cartel is the main source of resistance and opposition to both human bioenhancement and colonization of the universe, as the main human project for this millennium.

$>$ The anthropocentric stance against colonization of the universe is incoherent and implies magical, rather than scientific, way of thinking.

$>$ The argument for delayed human exploration and colonization of the universe is, like any other delay-type argument, just a cop-out for avoiding responsibility which resolves nothing of substance.

In the following sections (2 -5) I shall consider each of these theses in some detail, before summarizing the threat to human progress and flourishing in the concluding section. ${ }^{1}$

\section{Anthropocentric cartel and its discontents}

Anthropocentrism can best be understood as assigning special position to humans in either spatiotemporal, or some other parameter space of relevance in any particular field or assigning special teleological importance to homo sapiens. Naïve versions of anthropocentrism were related to our spatiotemporal position in the universe, or our position in the terrestrial biosphere - and have been efficiently dispelled by the Copernican and Darwinian revolutions. This applies to the $20^{\text {th }}$-century follow-ups of the latter, in particular the physical-cosmological and molecular-biological revolutions in science.

Copernicus and his followers showed that there is no astronomical - or indeed any physicalscience-related - reason to assign special position to humans, our planet, our planetary system, or even, in the modern extension, our Galaxy. Darwinism was, in a sense, an extension of Copernicanism, not along the spatial scale, but along the dimensions of historical origin and complexity. Cognitive sciences extended this into the domain of mental phenomena, successfully linking them to many of our inherited traits, and the ongoing revolution in the field of artificial intelligence threatens to relegate our allegedly supreme and exalted cognitive powers to a rather modest place where they belong in a wider scheme of things (still best elaborated by Mazlish 1967); the discovery of an extraterrestrial intelligence - predominantly likely to be much more advanced than ourselves - will have the same effect (Ćirković 2017, and references therein). Other applied sciences and engineering have in various ways offered great contributions to the project of Copernicanism, and consequently have wrought havoc on our superiority complexes in domains ranging from social sciences like economics or linguistics, all the way toward arts and humanities, where we encounter modern digital arts, techno music, and many other forms of pop-cultures in which the role of human creator is at least decentred.

In light of all this, it is prima facie strange that the anti-Copernican tendencies are not only still strong, but according to all signs have experienced quite a revival in recent years. One might

\footnotetext{
${ }^{1}$ Some further elaborations, with the emphasis on the space-colonization imperative, are in Ćirković (2014, 2019).
} 
naively think that rejection of Copernicanism is a steep price, unlikely to be paid by anybody except a few religious zealots stuck in the Middle Ages. Unfortunately, this is far from being the truth and, if anything, anti-Copernican activities of the anthropocentric cartel have grown stronger since about the turn of the century. It is obviously a cartel according to the definition above, since it gathers wildly heterogeneous groups, individuals, and ways of thinking, with the common denominator of either vested interests in anthropocentric institutions permeating our society, or ideological blindness for reality underpinning the successes of the scientific method. Wide and dense anti-Copernican front encompass people ranging from opponents of animal rights and other defenders of anthropocentric legal orthodoxies to various either religious conservative or social-constructivist "warriors on science" and their various allies, from the Discovery Institute, to anti-vaccination lobbies to NaturalNews, Greenpeace, Union of Concerned Scientists, and other promoters of anti-GMO hysteria, to self-proclaimed "progressive humanists" incapable of dealing with the rational facts of science on a psychological level (including indubitably enlightened people like Hannah Arendt or Michael Frayn ${ }^{2}$ ), to radical futurists believing we need ideological anthropocentrism to ensure the perceived desired future of humanity.

Fighters against perceived "scientism", or "scientific imperialism", or something nebulously dubbed the "hegemony of science", as well as others bothered by the alleged "coldness", or "insensitivity", or even "inhumanity" of modern science, a la Francis Fukuyama or Mary Midgley, hold hands both with anti-environmentalists who do not recognize Genesis 1:28-30 as the harmful Bronze Age superstition it really is, and extreme new-age environmentalists worshipping Gaia as - no surprise there!-the centre of the universe. Concerned guardians of the "humanistic canon", be it further specified as modern or postmodern, allegedly worried about the tough position of assorted social sciences and humanities in university curricula (ostensibly under attack from the Most Evil Dark Forces of science and engineering), join forces in the anti-Copernican camp with assorted media and religious pundits like Leon Kass portraying science and scientists in a uniform Dr Victor Frankenstein's mould. When Kass (2007) preaches that

[s]cientific ideas and discoveries about living nature and man, perfectly welcome and harmless in themselves, are being enlisted to do battle against our traditional religious and moral teachings, and even our self-understanding as creatures with freedom and dignity

he incites the basest conservative instincts (our traditional religious/moral teachings are under attack! Moral panic! Moral panic!), but also performs an insidious demagogic maneuver by alleging that our self-understanding is of necessity correct and good. And to all these instances, one should add legions of their less sophisticated counterparts in much of the developing world, often blending local superstitions and ill-conceived "postcolonial" irrational nonsense into the antiscientific mix (e.g., the "explaining", in large parts of sub-Saharan Africa, of illnesses, AIDS included, as being caused by black magic) and preying on poor educational and

\footnotetext{
${ }^{2}$ Arendt [1967] (2007); Frayn (2006).
} 
public outreach standards still prevailing in many places. In spite of much effort by various environmental groups, in the twenty-first century, a mass murderer of animals, including our closest mammalian and even primate relatives, is still celebrated as a "capable hunter," while nobody would attach that label to, for instance, members of Al-Qaeda or the Norwegian farright terrorist Anders Behring Breivik, who was convicted for killing 77 people, including 69 children, in 2011.

It would not be an overstatement to claim that anti-Copernicanism in one form or another dominates $99 \%$ of public life and thought on this planet-which still serenely revolves around the Sun, an insignificant speck on the periphery of the Milky Way, with our Galaxy itself being only a smudge of light at the outskirts of the Local Supercluster. Evolution goes on, irrespectively of our parochial nonsense, throughout the $99.99999 . . \%$ of the world; the fact that even formally distinguished intellectuals can completely ignore this simple fact in their thinking is flabbergasting.

Thus, the job of the Copernican revolution is still quite an actual, timely, and risky concern. While the Inquisition which condemned Galileo seems unlikely to receive any open support today, I submit that this is more due to their old-fashioned garments and politically incorrect language than any true dissonance of ideas. After all, the underlying concern stays the same: worry about the perceived "well-being of humanity" and its institutions being threatened by "cold" and "soulless" science and technology, as well as the specter of "scientific imperialism" and similar linguistic concoctions devoid of meaning and reason, but quite appealing to worse angels of our nature (to paraphrase Abraham Lincoln, as well as Pinker 2011).

The focus of the odium has shifted from astronomy in Galileo's time to evolutionary biology, computer science, and environmental science today, but the underlying reality remains the same: below a thin skin of modernity often threatens a surprisingly medieval anthropocentrism. As summarized by the great computer scientist Edsger Dijkstra, "Science is hated because its mastery requires too much hard work, and, by the same token, its practitioners, the scientists, are hated because of their power they derive from it."

Even in science itself, the Copernican revolution often looks like an unfinished business, and indeed many scientists aid and abet the tide of anti-Copernicanism in various ways: by condoning various anthropocentric social and political mores, especially in animal ethics and environmental science; by reintroducing teleological elements into science even where it is clearly unnecessary; by accepting some of the postmodern nonsense about the social construction of physical reality; by seeking "deep" reasons beneath obvious coincidences; by subscribing to conspiracy theories outside one's own discipline; by condoning the abuse of science by politicians, clergymen, and self-proclaimed "humanistic scholars" whenever it suits their own ideological prejudices; and so on. For a particularly egregious recent example, see Comfort (2019). 
Like any drug carter, the anthropocentric cartel offers the pretence of legitimate business dealings: it offers its clients merchandise at a price in a voluntary deal. Except that, just in any other drug deal, the offer is deep down dishonest and the deal is not really voluntary.

\section{The unbearable lightness of essentialism}

The main opposition to the human bioenhancement comes from bioconservatives like Leon Kass who abhor "playing God" and possibly jeopardizing some mystical "human nature" or "human essence"; the other wing, not really that difficult, but tactically less exposed at this juncture consists of people on the self-proclaimed humanist left such as Leon Wieseltier. In the bioethics debate, this side is well-represented by e.g., Agar (2010); Sparrow (2013). This form of essentialism presents a continuity with other forms of essentialism going back to Aristotle and the Aristotelian misconstruals popular in the context of medieval philosophical thought. A modern rehashing of this scholastic dogmatism has been formulated by Fukuyama (2002), who argues for a mystical "factor $X$ ", admittedly unknown and unclear, but endangered by our biotechnological meddling and our transhumanist ambitions. In Fukuyama's view, we may be able to enhance humans in both physical and intellectual sense, while losing the "factor $X$ " in the process, and thus being necessarily at the net loss. He goes further and claims that the transhumanist idea of taking control of our own evolution is "the most dangerous idea" - with the implication that (pseudo)random chance is somehow safe. This is obviously in conflict with the thrust of the evolutionary thinking about the origin of humans (Diamond 1992; Sober 1993; Povinelli 2004; the chapter by Christopher Wills in Bostrom and Ćirković 2008).

Why limit oneself to just abstract moral or spiritual dimensions? A part of the localization of essentialism is just a well-disguised geocentrism, which manifests itself in the rejection of space travel (at least insofar it involves humans) and, in more pathological forms, even the rejection of the entire field of astrobiology (Malazita 2017). Why should humans remain on Earth for all times, unless one does believe, with Aristotle, that it is humans' unique proper place? In stark contrast to Tsiolkovsky's dictum (often incorrectly cited to refer specifically to Earth) that "[a] planet is the cradle of mind, but one cannot live in a cradle forever," anthropocentrism is a doctrine of eternal infantilism, arbitrary limits, and ultimately closed mindedness.

As Owe (2019) cogently writes:

It is easier for us to believe that the solutions to the current global problems are external to us, but the external instruments we possess, such as technology and policy, cannot handle these issues unless they are controlled by morally responsible people. The same could be said for major projects along the multiplanetary trajectory, such as terraforming. I would argue that these psychological shortcomings relative to the social and natural environment we have transformed so radically by scientific technology, constitute an internal existential risk. If moral bioenhancement may help us overcome the existential risks the entirety of terrestrial life now faces, then I argue it is something we should seriously consider. 
Here we see an emerging synergy of the great projects of human enhancement and space colonization, as refracted through the same ethical lens. Radical transformative technologies pose new and unexpected problems, which we need to face, and not bury our heads in the sand or treat them as business as usual.

\section{Grand irony: anthropocentrism and the obsolescence of humans}

As we have seen, the resistance to human colonization of space comes in two flavours, the "theoretical" worries about the Evil Words (they are talking about "colonization", ergo Moral panic! Moral panic!) and other postmodern fashionable nonsense, and the "pragmatic" wing which highlights the practical costs and risks of crewed spaceflight. While one can easily identify some rational and well-meaning critics in the latter group (e.g., Weinberg 2013; Szocik $2019 b$ ), we can clearly see that this type of criticism is either very temporary, or merges smoothly with a flavour of the anthropocentric cartel rhetoric. The most merciful construal is the "robots are better" argument: we have nothing against space travel as such, we admit its values, but we need to admit and accept that robotic probes and spacecraft are much better, cheaper, and less risky than crewed spaceflight. That is, while there is an intrinsic value to be found in space, in terms of both knowledge and economic resources, we should not send people after them, only robots.

The biggest irony of the "robots are better" argument is obvious to all but the most extreme anthropocentrics still slouching out of the woodwork. If robots are indeed better - in all relevant senses - at space exploration than humans, than robots are arguably better at everything else than humans. Not just in playing chess and go, or cleaning carpets, or answering phone calls, or driving trucks, or sex. Space exploration, taken generally and seriously, not just the pitiful baby steps we have made so far, is more complex and involved than any of these human activities. Now, a key question looms here: Maybe robots are better at writing "philosophical" criticisms of human space exploration as well? In a Monty-Pythonesque way, it obtains something of a Gödelian flavour.

Space exploration is indubitably both science and technology, especially when we take it in medium- and longer-term sense; and one might argue that it has an important artistic aspect as well (e.g., Malina 1991; Sagan 1994; Ono 2010). So, people who are arguing that humans should relinquish space exploration in favour of robots seem to be arguing that humans could, at least in principle, relinquish any other hitherto human activity. And since robots are already immensely better than humans in so many different activities, from operating heavy machinery to driving in heavy traffic to playing chess and go to operating customer service call centres, after just a blink of an eye in historical and evolutionary terms, there is every reason to think they will be superior in other fields as well before long. So, maybe Karel Čapek - together with some of the modern transhumanist thinkers like Kurzweil or Moravec - was entirely correct that humans should give the way to the next, superior stage in evolution. 
Thus, the opponents of human spaceflight who take the "robots are better" road argue that humans are effectively obsolete. This is obviously in contradiction with the anthropocentric attitude of the critics. The wiggle room there is that they assume robotic probes will always and necessary be simple things similar to the Mariner and Pioneer spacecraft; this is incoherent, since such simple automata could never be competitive with human explorers. ${ }^{3}$ In order to be equivalent and superior to humans as explorers, future spacefaring robots need to be sophisticated Al systems, capable of independent decision-making, conceiving new research programs in situ, or modifying the ongoing programs in light of contingent circumstances, etc. In light of ever-increasing communication delays between the probe and mission control, their autonomy will be of paramount importance.

In light of all this, it turns out that opponents of human space exploration and colonization will need to resort to some kind of repression, similar to that shown in Sir Ridley Scott's magnificent Blade Runner (1982) movie in order to sustain the anthropocentric dogma. Recall that in the movie androids are only allowed in space colonies ("Off-world") and prohibited on Earth on the pain of state-sponsored summary execution. Presumably, the prohibition is instituted exactly because androids are both physically and intellectually superior to humans, which is also the reason they have an artificially shortened lifetime. That form of discrimination is, of course, both immoral (as argued by the movie) and stupid, likely to be unsustainable in the long run. It is also hinted - for instance in the famous monologue of the leader of rebel androids, Roy Batty, to the protagonist, Deckard, on that rainy roof - that at least a part of the androids' superiority exactly comes from their exposure to experiences in space, which are favourably contrasted with the narrow horizon of the masses of people remaining on Earth. Do we really wish for a Blade Runner-like future of humanity?4

\section{Passing the buck}

The argument for delaying space exploration/colonization by humans is occasionally proposed as a "realistic" middle ground between proponents of the cosmic future of humanity and those who would burn them at stake as heretics/witches/Dr. Frankensteins. The argument roughly goes like this: right now, it is not a good time for human exploration and colonization, but at some point in the future the time will be right. Recent good representatives in this category are Weinberg (2013), Schwartz (2019), or Szocik (2019a,b); these should be separated from fundamentalist and more toxic criticisms, such as that of Westfahl (1997), Slobodian (2015), Kriss (2017), Torres (2018), or Vidaurri (2019). Here, I wish to argue three points related to the argument for delay: first, that it is in part tautological and vague; second, that it contains

\footnotetext{
3 The incoherency is usually swept under the rug by various rhetorical tricks and appeals to emotions.

${ }^{4}$ Actually, many in the anthropocentric cartel would prefer futures even worse than the Blade Runner, where it is implied that at least some humans live off-world and participate in the grand exploration and colonization feats. Cf. Klee (2017); Torres (2018) for views that humans could and should not leave Earth at all.
} 
conveniently hidden assumptions of rather questionable nature; and third, that it is morally suspicious in the same manner and at least in the same amount as the analogous argument for the delay in climate change actions.

First, since there is no known "natural" timescale for any particular occurrence in human cultural evolution, it is very difficult to objectively assess this argument. How big delay is "sufficient"? Or "optimal"? Or "desirable"? Proponents refrain from going open on this central issue. On one hand, the fact that I am writing this now and not working directly on space science and technology, could be construed as my support to some degree of delay. On the opposite pole, someone who would claim that human space activities should be postponed for a billion years, should not be taken seriously in the first place. Usually, we are seeing some vague construals such as "it is a task for the distant future" (Weinberg 2013) or empty platitudes such as "once we have figured out how to make life on Earth work in an environmentally and politically sustainable way" (Williams 2010).

Second, the major questionable assumption of the argument for delay is that we are indeed free to delay it according to our will and intentionality. In other words, the assumption is that there is no well-defined (albeit unknown) window of opportunity for at least the onset of the human colonization of space. In view of the recent work in astrobiology, for instance, the absence of such window looks highly unlikely (e.g., Chopra and Lineweaver 2016). Everything in evolution, including biological and cultural evolution, seems to occur in windows of opportunity and it is quite possible that, once we blew the first chance - or the first couple of chances - there would not be further ones forthcoming. In particular, it is exactly those extreme global catastrophic risks (one of the major motivations for human space exploration and settlement) which might prevent further possibilities by what bioethicists Ingmar Persson and Julian Savulescu call "the ultimate harm" (Persson and Savulescu 2012). Even a gradual process, such as climate change still is, creates dangerous feed-backs in slowing down economic activity which, ironically, may reduce future emissions and offset some of the natural feed-back cycles (Woodard, Davis, and Randerson 2019; Caldeira and Brown 2019), without significant reduction in price of further action.

Third, I submit there is no structural difference between the argument for delaying of space colonization and the infamous argument for delaying climate action. In both cases there is a gasping presumption that we shall inevitably be in some generalized sense better off in the future than we are now: it is usually said that particular climate change mitigation measures which are expensive today will become much cheaper in the future, so we should undertake them 20 years from now, say. Or 50 years. Or a hundred. Clearly, irresponsibility and naivete of such a view defy belief. Adverse consequences of climate change are what threatens - to a large degree - global economic prosperity today, which is a precondition for the decrease in price tomorrow. While the question which model of temporal discounting best represents reality still lacks clear answer, nobody seriously doubts the necessity of such discounting in the 
futures studies. Neither are catastrophic consequences of the delayed climate change action a secret any more (Mengel et al. 2018).

Why should it differ for human space exploration and colonization? Insofar as space colonization is regarded as decreasing the risk of human extinction and increasing the chance of preserving human values, the parallel holds. While it is conceivable that, barring crises and catastrophes, direct costs of human space colonization projects will decrease in the future, one is still entitled to the same scepticism toward this economic reasoning as in the case of climate change above. Some of the sceptics are quite aware of that (e.g., Szocik 2019b). For all the noble talk about ecological awareness, social justice, and other shibboleths, the cartel is just a bunch of early humans afraid to go on two legs, afraid to go into a dark cave, afraid to start a fire, afraid of a storm, or of a gust of wind, or of a tiger or a bear. And here we come upon the central cowardice of anti-space scepticism: (mis)using this primal fear to justify procrastinations and delays to do what is both useful and right.

\section{Instead of conclusions: say no to the Blade Runner}

We are living in perhaps the riskiest epoch of homo sapiens's existence: in addition to classical global catastrophic hazards such as asteroidal/cometary impacts or supervolcanic eruptions, there is a host of new and unprecedented risks stemming from misuse of powerful technologies, like nuclear power, biotechnology, nanotechnology, and artificial intelligence (e.g., Posner 2005; Bostrom and Ćirković 2008). Studying and mitigation of these risks is a global priority in both moral and policy-related terms (Bostrom 2013). Both human bioenhancement and human colonization of space - starting, of necessity, with colonization of the Solar System - are ways to address both the research and practical aspects of this priority. Perhaps there are additional multiple ways of achieving the same goal; it is, however, incumbent on those who are opposed to these two compatible strategies to show that there are those additional ways and that they are feasible. However, a rather clear pathway - and not very novel or radical - is to extend (enhanced) human presence beyond Earth and beyond those hazards and catastrophes which are, by their physical nature, limited to the Earth system. All other benefits come on the top of that and as a bonus.

While human colonization of the Solar System and, ultimately, wider universe sounds utopian in many circles, a proponent should not dissipate energy in combating the moniker. Instead, it should be endorsed, for the wise reason the great designer, architect, and visionary Richard Buckminster Fuller has put in the title of one of his books, originally published in 1963: it is either utopia or oblivion (Fuller 2008). Of course, even earlier, H. G. Wells warned that the history of humanity is "a race between education and catastrophe" (Wells 1920). And education is hardly winning. 
To the best of our present-day reasoning about existential risks, immunity to such risks (with, perhaps, one or two exceptions) follows from a successful human colonization of the Solar System; let us therefore concentrate on this particular form of colonization of the universe, while noticing that, of course, there is a meaningful sense in which subsequent expansion into the Galaxy is much better still. It is clear why this is so: risks generically associated with the Earth system (asteroid impacts, supervolcanoes, global climate change) will be transcended by expansion of the spatial domain filled with humans and their values. The risks associated with our cosmic environment (giant Solar flares, close supernovae/GRBs, encounters with dense molecular clouds) will be overcome through increased understanding of their astrophysical mechanisms and the construction of protective measures using the same technologies necessary for undertaking the colonization in the first place. The measures to be undertaken to mitigate more extreme cosmic risks are tightly connected - as far as we can see today - with human control and management of the resources of the Solar System. For instance, this applies to constructing swarm shieldings for Earth and other local habitats in a case of predicted close supernova or a Galactic GRB (Ćirković and Vukotić 2016). Similar reasoning, however, is valid for other existential and global catastrophic risks. Risks associated with ecological imbalance and resource depletion will be transcended in an obvious way-by transcending the boundaries of the unique terrestrial ecosystem and vastly increasing the resource base (Zubrin 1999; Cockell 2007; deGrass Tyson 2012).

Even the two risks which are likely to stay with us in some form, cataclysmic warfare and technologically-enhanced totalitarianism, seems less dangerous in the extended domain of colonized space than on Earth. While warfare will remain possible unless the outcome of social and political evolution is a singleton, it will be less likely to destroy all multiple ecosystems of an expanding humanity; whereas on Earth, one nuclear or supervolcanic winter would be enough. And the diversity of habitats will necessarily increase the diversity of modes of thinking, something by definition antithetical to all totalitarian projects; in addition, the latency imposed by large distances in space might be a further obstacle to enforcement by any centralized authority. ${ }^{5}$

Conclusions about ethical value of space exploration and colonization hold irrespectively of one's moral preferences; in particular this is true irrespective of whether one trusts consequentialist/utilitarian intuitions in estimating our "cosmic endowment" (Bostrom 2003) in terms of value in information, (post)human lives, or any other way. Quite to the contrary, this is a perfect example of an issue capable of uniting people of various philosophical, ideological, and ethical bents in the same manner as it can unite different other seemingly opposed strands of the present-day cultural fabric. In one sense, the answer to questions often posed about the purposelessness of modern-day humans - e.g., in critical reactions to Pinker's (2018) book - is

\footnotetext{
5 However, see Cockell (2008).
} 
exactly safeguarding of human species and human accomplishment against risk from existential catastrophes, or the "ultimate harm" of Persson and Savulescu (2012).

Even if no such global cataclysm occurs, humans could become obsolescent through evolutionary means exactly because of our relinquishment of space exploration and colonization. That people talk less about slow dysgenic pressures does not make them any less real. In the long run, there is no difference between isolated planet Earth and an isolated island like Rapa Nui: everything which has happened in any isolated local system like Rapa Nui will necessarily happen on Earth in the fulness of time. Of course, one could negate the temporal qualification by appeal to the Solar evolution and the accompanying increase in luminosity; but even in the most pessimistic accounts, there is still about 1 Gyr, before the Earth becomes uninhabitable, which is more than enough time to play out all options of human history (or tragedy, if we willingly accept the Rapa Nui approach and neglect the wider universe). Of course, the very same projects attacked by the cartel, human bioenhancement and space colonization, could mitigate these dysgenic processes; it is, therefore, quite natural that they are developed in parallel (cf. Szocik and Braddock 2019).

Not that there is any real trend in favor of space colonization either in our navel-gazing civilization; as warned by Nunn et al. (2014), we are already in a highly disturbing situation in which the annual cost of obesity in the USA is about 12 times larger (!!!) than the annual cost of the national space research and exploration programs. That the anti-space sentiment has become completely normative is obvious to such extent that even a self-professed believer in science and progress like Steven Pinker calls space colonization a "nonstarter", proposed by "naifs" [Pinker 2018, p. 390]. In light of this reality, all this frantic anti-space opposition looks more and more like flogging of a dead horse. The work of the anthropocentric cartel, as exemplified by some of the works quoted above, has been remarkably successful thus far; not that much by directly obstructing our progress in science and technology, but in inventing and advertising various justifying narratives which divert both attention and resources from our global priorities in Bostrom's sense (Zubrin 2011; Autri and Skran 2019; Ćirković 2019). And there is absolutely no warrant that all this distraction and diversion will not turn into something much worse, similar to what has happened with many strands of anti-nuclear movement or deep ecology/ecoterrorist groups.

One should be crystal-clear about one thing: contemporary anthropocentrism is a deep and insidious form of anti-humanism. Problems, difficulties, calamities, even catastrophes and existential risks facing humanity are always welcomed by the cartel, usually as a motivation for smug, self-congratulatory, and self-indulgent messages of pessimism. It is either the need of "humbleness before the divine", or "the tragic view of the human nature", or even "respect for untamed wilderness of other worlds", or some similar hollow ideological mantra of the day. The obvious naivete of these and of some of the actors parroting them should not blind anyone in thinking they are not dangerous in the extreme. On the contrary, by covering up the detrimental loss of adventuring and exploratory spirit, as well as the expansion drive, by 
superficially sophisticated arguments, the academic wing of the anthropocentric cartel inflicts immeasurable damage to the welfare and the very existence of future generations of humanity.

Acknowledgements. Foremost thanks go to the Editor, Konrad Szocik, for his diligent work on promoting serious thought about cosmic futures of humanity, as well as to Vojin Rakić for sharing his overarching vision of modern, future-oriented bioethics which has been a constant and enormous inspiration. The author also wishes to express gratitude to Richard Cathcart, Andrea Owe, Branislav Vukotić, Ksenija Petrović, Zoran Živković, Jelena Dimitrijević, Anders Sandberg, George Dvorsky, John Smart, Slobodan Perović, Karl Schroeder, Aleksandar Obradović, Milan Stojanović, S. Jay Olson, Goran Milovanović, Srdja Janković, and the late Damian Veal for stimulating discussions on the subject matter of this essay. The author has received financial support from the Ministry of Education, Science and Technological Development of the Republic of Serbia through the projects \#ON176021 and \#ON179048.

\section{References}

Agar, N. 2010, Humanity's End: Why We Should Reject Radical Enhancement (MIT Press, Cambridge).

Arendt, H. [1963] 2007, "The Conquest of Space and the Stature of Man," New Atlantis Fall issue, 43-55 (http://www.thenewatlantis.com/publications/the-conquest-of-space-andthe-stature-of-man, last accessed August 15, 2019).

Autri, G. and Skran, D. 2019, "Humanity Can't Afford to Keep Space Pristine," Foreign Policy (https://foreignpolicy.com/2019/10/30/nasa-space-exploration-mars-city-muskhumanity-keep-space-pristine/, last accessed November 15, 2019).

Bernstein, L. 2002, The Greatest Menace: Organized Crime in Cold War America. Boston: UMass Press).

Bostrom, N. 2003, "Astronomical Waste: The Opportunity Cost of Delayed Technological Development," Utilitas 5, 308-314.

Bostrom, N. 2013, "Existential Risk Prevention as Global Priority," Global Policy 4, 15-31.

Bostrom, N. and Cirković, M. M. (eds.) 2008, Global Catastrophic Risks (Oxford University Press, Oxford). 
Caldeira, K. and Brown, P. T. 2019, "Reduced emissions through climate damage to the economy," Proceedings of the National Academy of Sciences 116, 714-716.

Chopra, A. and Lineweaver, C.H. 2016, "The case for a Gaian bottleneck: the biology of habitability," Astrobiology 16, 7-22.

Cirković, M. M. 2014, "The Greatest Gamble in History," Collapse 8, 385-415.

Ćirković, M. M. 2017, "Enhancing a Person, Enhancing a Civilization: A Research Program at the Intersection of Bioethics, Future Studies, and Astrobiology," Cambridge Quarterly of Healthcare Ethics 26, 459-468.

Ćirković, M. M. 2019, "Space colonization remains the only long-term option for humanity: A reply to Torres," Futures 105, 166-173.

Ćirković, M. M. and Vukotić, B. 2016, "Long-Term Prospects: Mitigation of Supernova and Gamma-Ray Burst Threat to Intelligent Beings," Acta Astronautica, 129, 438-446.

Cockell, C.S. 2007, Space on Earth: Saving our World by Seeking Others (Macmillan, London).

Cockell, C. S. 2008, "An Essay on Extraterrestrial Liberty," Journal of the British Interplanetary Society $61,255-75$.

Comfort, N. 2019, "How science has shifted our sense of identity," Nature 574, 167-170.

deGrass Tyson, N. 2012, Space Chronicles: Facing the Ultimate Frontier (Norton, New York).

Diamond, J. 1992, The Third Chimpanzee (HarperCollins, New York).

Frayn, M. 2006, The Human Touch: Our Part in the Creation of a Universe (Faber and Faber, London).

Fukuyama, F. 2002, Our Posthuman Future: Consequences of the Biotechnology Revolution (Farrar, Straus \& Giroux, New York).

Fuller, B. R. 2008, Utopia or Oblivion: The Prospects for Humanity (Zürich: Lars Müller,)

Kass, L. R. 2007, "Keeping Life Human: Science, Religion and the Soul," Wriston Lecture, Manhattan Institute for Policy Research (https://www.manhattaninstitute.org/htm/ 2007 -wriston-lecture-keeping-life-human-science-religion-and-soul8894.html, last accessed 1 November, 2019).

Klee, R. 2017, "Human expunction," International Journal of Astrobiology 16, 379-388.

Kriss, S. 2017, "Think Twice About Escaping Earth to an Exoplanet," The Atlantic March 2017, https://www.theatlantic.com/science/archive/2017/03/space-travel-wont-save-youfrom-capitalism/518853/ (last accessed May 27, 2019). 
Lomborg, B. 2001, The Skeptical Environmentalist: Measuring the Real State of the World (Cambridge University Press, Cambridge).

Malazita, J. W. 2017, "Astrobiology's Cosmopolitics and the Search for an Origin Myth for the Anthropocene," Biological Theory 13, 113-120.

Malina, R. F. 1991, "In defense of space art: The role of the artist in space exploration," in International Astronomical Union Colloquium, Vol. 112 (Cambridge University Press, Cambridge), 145-152.

Mazlish, B. 1967, "The Fourth Discontinuity," Technology and Culture 8, 1-15.

Mengel, M., Nauels, A., Rogelj, J. and Carl-Friedrich Schleussner, C.-F. 2018, "Committed sealevel rise under the Paris Agreement and the legacy of delayed mitigation action," Nature Communications 9, 601 (1opp).

Nunn, A. V. W., Guy, G. W., and Bell, J. D. 2014, "The intelligence paradox; will ET get the metabolic syndrome? Lessons from and for Earth," Nutrition \& Metabolism 11, 34 (13pp).

Ono, A. 2010, "Art: Art as a Psychological Support for the Outer Space Habitat," in Lunar Settlements, pp.197-214.

Owe, A. 2019, Environmental Ethics in Outer Space: A macrostrategic space journey through cosmism, posthumanism and moral enhancement, Master's Thesis in Development, Environment and Cultural Change, University of Oslo (https://www. duo.vio.no/bitstream/handle/10852/69331/1/Owe-Andrea-15-05-2019Environmental-Ethics-in-Outer-Space-MAthesis-.pdf).

Persson, I. and Savulescu, J. 2012, Unfit for the future: The need for moral enhancement (Oxford University Press, Oxford).

Pinker, S. 2011, The better angels of our nature: Why violence has declined (Penguin Books, New York).

Pinker, S. 2018, Enlightenment Now: The Case for Reason, Science, Humanism, and Progress (Penguin Books, New York).

Posner, R. A. 2005, Catastrophe: Risk and Response (Oxford University Press, Oxford).

Povinelli, D. J. 2004, "Behind the ape's appearance: Escaping anthropocentrism in the study of other minds," Daedalus 133, 29-41.

Sagan, C. 1994, Pale Blue Dot: A Vision of the Human Future in Space (Random House, New York).

Schwartz, J. S. 2019, "Space settlement: What's the Rush?" Futures 110, 56-59. 
Slobodian, R. E. 2015, "Selling space colonization and immortality: A psychosocial, anthropological critique of the rush to colonize Mars," Acta Astronautica 113, 89-104.

Sober, E. 1993, Philosophy of Biology (Westview Press, Boulder).

Sparrow, R. J. 2013, "The perils of post-persons," Journal of Medical Ethics 39, 80-81.

Szocik, K. 2019a, "Should and could humans go to Mars? Yes, but not now and not in the near future," Futures 105, 54-66.

Szocik, K., 2019b, Human Place in the Outer Space: Skeptical Remarks. In The Human Factor in a Mission to Mars (pp. 233-252). Springer, Cham.

Szocik, K. and Braddock, M. 2019, "Why Human Enhancement is Necessary for Successful Human Deep-space Missions," The New Bioethics 25, 295-317.

Torres, P. 2018, "Space Colonization and Suffering Risks: Reassessing the 'Maxipok Rule'," Futures 100, 74-85.

Vidaurri, M. 2019, "What happens when you leave empty seats at the table?" The Space Review (October 21, 2019) http://www.thespacereview.com/article/3817/1.

Weinberg, S. 2013, "Response: Against manned space flight programs," Space Policy 29, 229230.

Wells, H. G. 1920, The Outline of History: Being a Plain History of Life and Mankind (Macmillan, New York).

Westfahl, G. 1997, "The case against space," Science Fiction Studies 24, 193-206.

Williams, L. 2010, "Irrational Dreams of Space Colonization," Peace Review 22, 4-8.

Woodard, D. L., Davis, S. J., and Randerson, J. T. 2019. Economic carbon cycle feedbacks may offset additional warming from natural feedbacks. Proceedings of the National Academy of Sciences 116, 759-764.

Zubrin, R. 1999, Entering Space: Creating a Spacefaring Civilization (Jeremy P. Tarcher/Putnam, New York).

Zubrin, R. 2011, Merchants of Despair: Radical Environmentalists, Criminal Pseudo-Scientists, and the Fatal Cult of Antihumanism (Encounter Books, New York). 